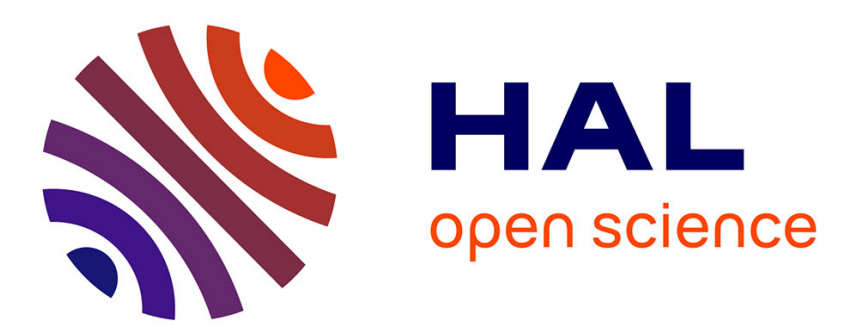

\title{
Viral inactivation of human bone tissue using supercritical fluid extraction
}

Jacques Fages, B Poirier, Y Barbier, P Frayssinet, Marie-Line Joffret, W Majewski, G Bonel, D Larzul

\section{- To cite this version:}

Jacques Fages, B Poirier, Y Barbier, P Frayssinet, Marie-Line Joffret, et al.. Viral inactivation of human bone tissue using supercritical fluid extraction. ASAIO Journal, 1998, 44 (4), pp.289-293. hal-01697287

\section{HAL Id: hal-01697287 \\ https://hal.science/hal-01697287}

Submitted on 21 Mar 2018

HAL is a multi-disciplinary open access archive for the deposit and dissemination of scientific research documents, whether they are published or not. The documents may come from teaching and research institutions in France or abroad, or from public or private research centers.
L'archive ouverte pluridisciplinaire HAL, est destinée au dépôt et à la diffusion de documents scientifiques de niveau recherche, publiés ou non, émanant des établissements d'enseignement et de recherche français ou étrangers, des laboratoires publics ou privés. 


\title{
Viral Inactivation of Human Bone Tissue Using Supercritical Fluid Extraction
}

\author{
Jacques Fages, ${ }^{*}+$ Béatrice Poirier, $\neq$ Yves Barbier, $\neq$ Patrick Frayssinet, + Marie-Line JOffret, $\neq$ \\ Wieslaw Majewski, $\S$ Gllbert Bonel, $+\|$ and Daniel Larzul $\neq$
}

\begin{abstract}
A new bone tissue process using supercritical carbon dioxide fluid extraction (SFE) has been evaluated for its ability to inactivate or eliminate viruses. Four viruses, human immunodeficiency virus type 1 (HIV-1), Sindbis virus, polio Sabin type I virus, and pseudorabies virus (PRV), were exposed to four different processing steps. In addition to supercritical $\mathrm{CO}_{2}$, hydrogen peroxide, sodium hydroxide, and ethanol treatments were evaluated. The mean cumulated reduction factors $\left(\log _{10}\right)$ for the four viruses exposed to these four steps were $>\mathbf{1 4 . 2}$ for HIV-1, $>\mathbf{1 8 . 2}$ for Sindbis virus, $>\mathbf{2 4 . 4}$ for poliovirus, and $>\mathbf{1 7 . 6}$ for PRV. The mean reduction factors obtained by the supercritical fluid extraction alone were $>4.0,>4.3$, $>6.6$, and $>4.0$, respectively. These results demonstrate that the SFE process is effective in inactivating viruses on human femoral heads, and provides a level of inactivation similar to that obtained by traditional cleaning methods. It is proposed that $\mathrm{CO}_{2}$ SFE be incorporated as a routine step in the processing of bone allografts for transplantation either to replace or supplement existing procedures. ASAIO Journal 1998; 44:289-293.
\end{abstract}

Thro hroughout the world, there is an increasing need for bone grafts, especially in orthopedic, maxillofacial, trauma, and tumoral surgery. Because of the inherent limitations of autografts, such as their limited quantity, additional surgical procedures, and so forth, the use of allografts has increased considerably in popularity. ${ }^{1}$ Although allografts seem clinically well tolerated, immune reactions against osteochondral allografts have been detected in animals and humans. ${ }^{2}$ Moreover, histologic analysis of massive bone allografts has revealed that their osseointegration is poor, ${ }^{3}$ and this contributes to the antigenic reaction against the graft. ${ }^{4}$ One of the obstacles to bone integration is the presence of fat in the medullary tissue, which has proven to be antigenic ${ }^{5}$ and to slow down implant colonization.

However, the most critical limitation in the use of allografts is their risk of transmitting viral diseases. ${ }^{6}$ Transmission of the hepatitis $C$ virus, as well as human immunodeficiency virus type 1 (HIV-1), by tissue transplantation has been reported. ${ }^{7,8}$ Most of today's allografts, rather than being processed, are

From the *Ecole des Mines, Albi, +Bioland, Toulouse, $¥$ Texcell, Institut Pasteur, Paris, §Separex, Champigneulles, and IIInstitut National Polytechnique, Toulouse, France. stored frozen. ${ }^{9}$ To sterilize them, one of the following three processes is usually selected: $\beta$ - or $\gamma$-irradiation, ethylene oxide, or autoclaving. ${ }^{10,11}$ None of these three methods has proven to be totally satisfactory, either because of the resistance of some viruses to physicochemical processing or the loss of inductive or mechanical properties. ${ }^{12,13}$

A new bone tissue cleaning process with the potential to resolve this problem has been described by Fages et al. that uses supercritical fluid (SCF) technology. ${ }^{14}$ Above a critical pressure, $\mathrm{PC}$, and a critical temperature, Tc, pure compounds are neither gaseous nor liquid. They are in a third state called a "supercritical fluid." Because of their unique properties of diffusivity, density, and viscosity, supercritical fluids are used as selective solvents for extraction. Like liquids, they have a high density and consequently a high solvent capacity. What is remarkable is that this solvent capacity can be fine tuned to a significant extent by simply varying the working pressure or temperature.

The other physicochemical properties of SCFs are also of interest. In particular, they display gaslike transport properties because of their very low viscosity and very high diffusion coefficients. ${ }^{15}$ Therefore, they are particularly effective in extracting compounds trapped in a solid microporous matrix, as is the case with bone. In the medullary tissue, there are large amounts of lipids that are difficult to extract with liquid solvents because of this low wettability. However, they can be easily and completely extracted by SCF technology.

The use of a compound such as carbon dioxide provides a particularly safe and efficient method for removing fat because, when it is in a SCF state, it is known both for being no-toxic and as a good solvent for lipids. ${ }^{16}$ Supercritical $\mathrm{CO}_{2}$ extraction leads to a range of in-depth delipidation of the porous bone. Three additional steps are required to complete the processing of bone. They involve 1) hydrogen for the removal of protein and cellular debris, 2) sodium hydroxide for the inactivation of potential prions, and 3) ethanol for final cleaning and for its well known virucidal properties. ${ }^{17}$ Animal bone tissue processed through these four steps has been reported to osteointegrate rapidly ${ }^{18}$ while enjoying unmodified mechanical properties. $^{14}$

According to certain regulatory documents, ${ }^{19}$ one of the main ways to control potential viral contamination of biologics is to test the capacity of the preservation and sterilization process to remove or inactive viruses. The goal of this study was to evaluate the effectiveness of each of the four previously mentioned processing steps independently to inactive or remove viruses from human bone. This was accomplished by 1) spiking significant amounts of the relevant virus (viral load [Li]) 
in a preprocessed bone sample, 2) performing one of the four processing steps, and 3) recovering virus (viral load [Lf]) from the processed bone sample. The viral inactivation or elimination at each stage was quantified by calculating the reduction factor $(R)$, which is the $\log _{10}$ of the ratio Li/Lf.

\section{Materials and Methods}

\section{Materials}

The bones used were human femoral heads that had previously been checked for their serologic status.

The selection of viruses used in this study was influenced by the European Community guideline on validating virus inactivation (EC III/8115/89), which stipulates the following criteria: 1) include the major adventitious viruses in humans, such as HIV-1, hepatitis C, B, and A viruses, and herpesviruses; 2) include a range of resistance of the viruses to physicochemical treatments; and 3) include several of the major classes of viral classification, considering the viral genome (RNA or DNA) and the presence and absence of an envelope. The last two criteria were particularly pertinent when taking into account emerging viruses. To comply with these guidelines, the following four viruses were chosen to evaluate the process: 1) HIV-1 (RNA, enveloped, low resistance to physicochemical treatments, adventitious virus); 2) Sindbis virus (RNA, enveloped, low to medium resistance to physicochemical treatments; model for hepatitis $\mathrm{C}$ virus); 3 ) polio Sabin type I virus (RNA, nonenveloped, medium to high resistance to physicochemical treatments; model for hepatitis A virus); and 4) pseudorabies virus (PRV; DNA, enveloped, low resistance to physicochemical treatments; model for herpesvirus and hepatitis B virus).

\section{Methods}

Bone Processing Steps. Step 1: Supercritical Fluid Extraction. A pilot plant (Separex, Champigneulles, France) was used to perform the extraction and separation steps by batch processing. The system pressurized the cooled liquid $\mathrm{CO}_{2}$ by means of a metallic membrane pump and then heated the fluid to the extraction temperature. The extraction vessel, with a volume of $2.5 \mathrm{~L}$, was loaded with a titanium basket containing the bone samples. The extraction conditions involved maintaining the $\mathrm{CO}_{2}$ flow rate at $2 \mathrm{~kg} /$ hour at a pressure of 250 bars and temperature of $50^{\circ} \mathrm{C}$. The duration of the extraction step was calculated from 10 minutes for each gram of bone processed. After extraction, the fluid passed through three thermostatically controlled separation vessels in which the pressure was reduced in a stepwise manner. At the outflow of the last separator, the $\mathrm{CO}_{2}$ was liquefied and recycled.

Step 2: Hydrogen Peroxide Processing. The samples were exposed to a $35 \%$ (W/W) solution of hydrogen peroxide for 2 hours at a temperature of $40^{\circ} \mathrm{C}$.

Step 3: Sodium Hydroxide Processing. This step involved treating the samples with a $1 \mathrm{~mol} / \mathrm{L}$ solution of $\mathrm{NaOH}$ for 1 hour at $20^{\circ} \mathrm{C}$. The samples were then neutralized in an aqueous solution of $\mathrm{NaH}_{2} \mathrm{PO}_{4}(12 \mathrm{~g} / \mathrm{L})$.

Step 4: Ethanol Processing. The samples were immersed in a $95 \%$ aqueous solution of ethanol for 3 hours at $20^{\circ} \mathrm{C}$.

Viral Safety Evaluation of Each Step. The capacity of each processing step to inactivate or eliminate the viruses was evalu- ated separately for each virus at each step (Figure 1). To evaluate step $n$, bone pieces processed to step $(n-1)$ were spiked with a high quantity of virus and were then exposed to step $n$. The reduction factor (R) for step $n$ was calculated according to the European guidelines for blood derivatives and biotechnologic medicinal products. The value of $R$ reflects the loss of viral activity between the viral load before (Li calculated from piece CSM1) and after (Lf calculated from pieces CSM3 and CSM4) step $n$. A number of different controls were included to evaluate the influence of different parameters on the level of virus infectivity (Figure 1).

The presence or absence of viral infectivity in each bone piece was measured by plaque assays for Sindbis virus, poliovirus, and PRV, ${ }^{20}$ and by an infection assay for HIV-1. ${ }^{21}$ The level of infection was expressed as $50 \%$ of the tissue culture infection dose per milliliter $\left(\mathrm{TCID}_{50} / \mathrm{ml}\right)$ calculated using the Spearman Kärber formula for HIV-1, and in terms of plaque forming units per milliliter (PFU/ml) for the other viruses. ${ }^{22}$ For each step and for each virus, the detection limit of the titration assay depended on 1) the use of Poisson's formula with a $95 \%$ level of confidence, 2) the cytotoxicity of the tested solution, and 3) the volume of solution added to the cells. When no viral units were observed from spiked and processed bone specimens (pieces CSM3 and CSM4), the results were recorded as lower than the detection limit, and the corresponding reduction factors $R$ as higher than their calculated values (Table 1).

\section{Results}

\section{Validity of the Experimental Approach}

In addition to the reduction in viral load due to the four processes themselves, other parameters contributed to the loss of infectivity. For example, the length of time when the viruses were in the bone specimens (CSM1/CSM2) and the time during which the viruses were in suspension (V2/V3) are both factors that should be included.

On the other hand, the effects of centrifugation and the amount of viral activity recovered from the spiked bone specimens (V2/CSM1) were excluded from the calculation of $R$. The poliovirus without an envelope was recovered with no significant loss in activity. Its virus reduction factor was less than 1 compared with the initial viral load, whereas a less successful recovery rate was obtained for the three viruses with envelopes. The lowest value, that is, the greatest loss of viral activity in a bone specimen without processing, was observed with HIV-1. After spiking of the bone specimen preprocessed until step 3 , the observed reduction factor was $\log _{10} 2.9$.

Step 1 -Supercritical $\mathrm{CO}_{2}$. For the HIV-1, Sindbis virus, and polioviruses, there was a total absence of viral activity found on any of the processed bone specimens. The mean reduction factors for these three viruses were $4.05,>4.31$, and $>6.58$, respectively (Table $\mathbf{1}$ ).

For PRV, no activity was detected in the CSM4 specimen, whereas a very low remaining viral load was measured in the CSM3 specimen. The reduction factors, $R$, were $>4.03$ and 4.01 , respectively.

The apparent paradox of obtaining the highest reduction factors from the more resistant poliovirus can be explained in terms of the high initial level of recovery in the positive control specimen, CSM1. As with the three other viruses, no activity 


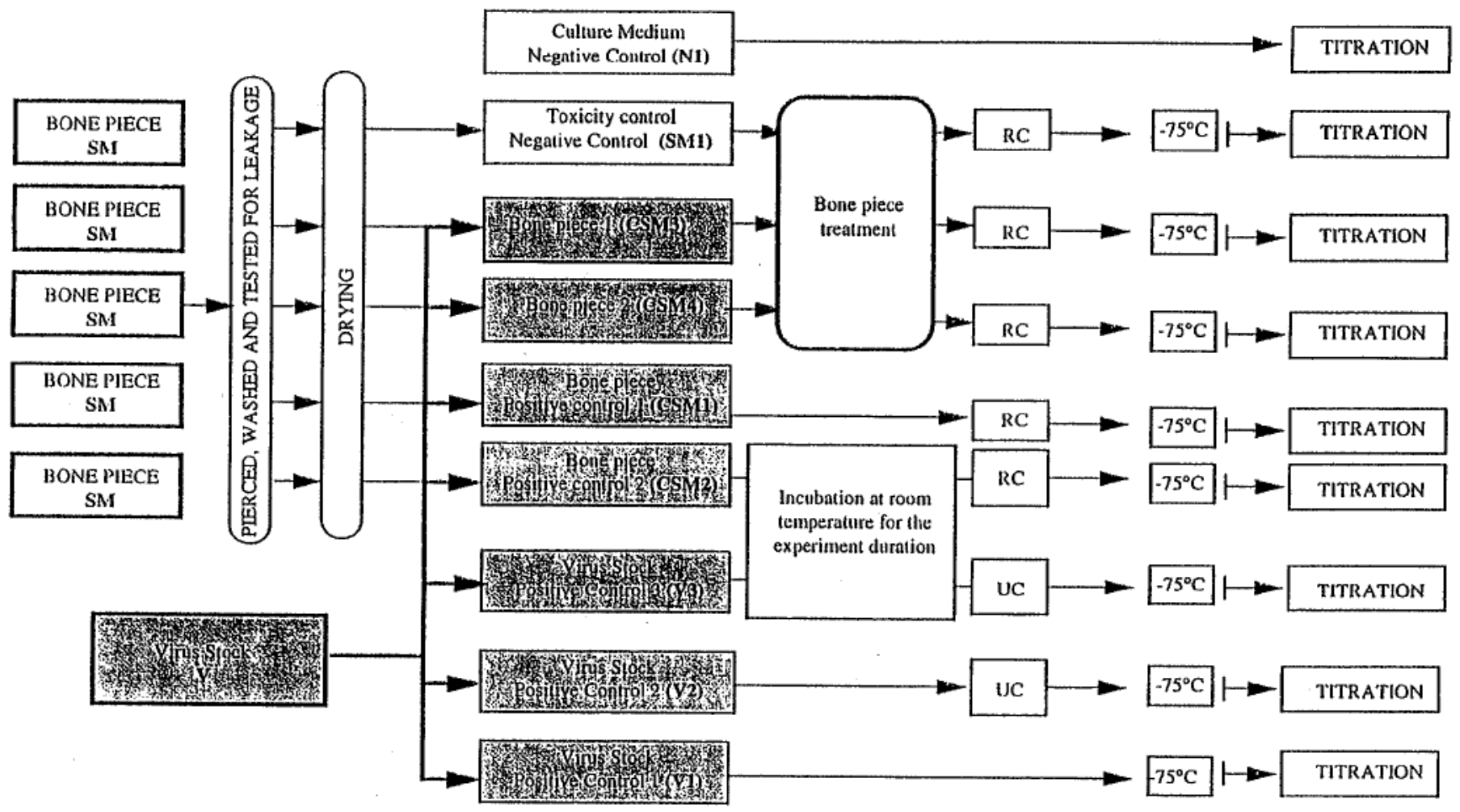

Figure 1. Schematic representation of the viral validation. UC, ultracentrifugation; RC, virus recovery conditions: Each bone piece was broken in small fragments, placed in culture medium for 1 hour at $4^{\circ} \mathrm{C}$, and centrifuged. The supernate was harvested and ultracentrifuged, and the pellet was resuspended in culture medium.

was found in the specimens after SCF processing. So, the higher reduction factors with the poliovirus were due to the higher initial activity level, not to differences in rates of inactivation between viruses.

Step 2-Hydrogen Peroxide. For HIV-1 and poliovirus, no viral activity was found in any of the processed bone specimens. As a result, their mean reduction factors were $>3.61$ and $>7.05$, respectively (Table $\mathbf{1}$ ).

For the Sindbis virus and PRV, no activity was detected in the CSM4 specimen, whereas a very low residual viral load was measured in the CSM3 specimens. The corresponding reduction factors were 4.41 and $>5.01$ for PRV, and 4.26 and $>5.52$ for the Sindbis virus. For the latter virus, the difference in reduction factors between duplicate specimens is significant, which may reflect a heterogeneity between the two bone pieces.

Step 3-Sodium Hydroxide. For HIV-1 and PRV, no viral activity was found in any of the specimens. For PRV, a high mean reduction factor for sodium hydroxide processing was obtained at $>4.66$, whereas a lower value, $>2.19$, was obtained for HIV-1 (Table 1). Two reasons may explain this low value. First, a very small proportion of the initial viral load was recovered on the "before processing" specimen CSM1, which led to a high preprocessing reduction factor of 2.87 . Second, the suspension added to the cells may have been cytotoxic because the first noncytotoxic dilution was $1 / 16$ (data not shown).

The Sindbis virus and poliovirus were not completely inactivated during the sodium hydroxide step, and their mean reduc- tion factors, $R$, were calculated to be 4.08 and 4.25 , respectively.

Step 4-Ethanol. For HIV-1, poliovirus, and PRV, no viral activity was found in any of the specimens, and the reduction factors were calculated to be $>4.38,>6.60$, and $>4.21$, respectively (Table 1).

For the Sindbis virus, a low remaining viral load was detected on the duplicate specimens, giving a mean reduction factor of 4.98 .

\section{Global Analysis}

The four bone processing steps were evaluated independently, with the bone specimens being exposed sequentially to each step up to the step to be evaluated. Because the inactivation conditions for each step were clearly independent, it is assumed that the step-specific reduction factors, $\mathrm{R}$, for each virus, can be aggregated to calculate a cumulative reduction factor, Rc, which represents the level of inactivation of process. However, the order in which the four processes were tested is important. The supercritical step must be the first because of the total range of in-depth delipidation thus achieved. The efficiency of the three following liquid steps is directly affected by the previous cleaning of the porous bone tissue.

As seen in Table 1, the global level of inactivation is high for all four viruses, with Rc values ranging from $>14.2$ to $>24.4$. The main reason for this broad range of results lies in the differing abilities of each virus to remain in the positive control specimens before processing, rather than in the pro- 


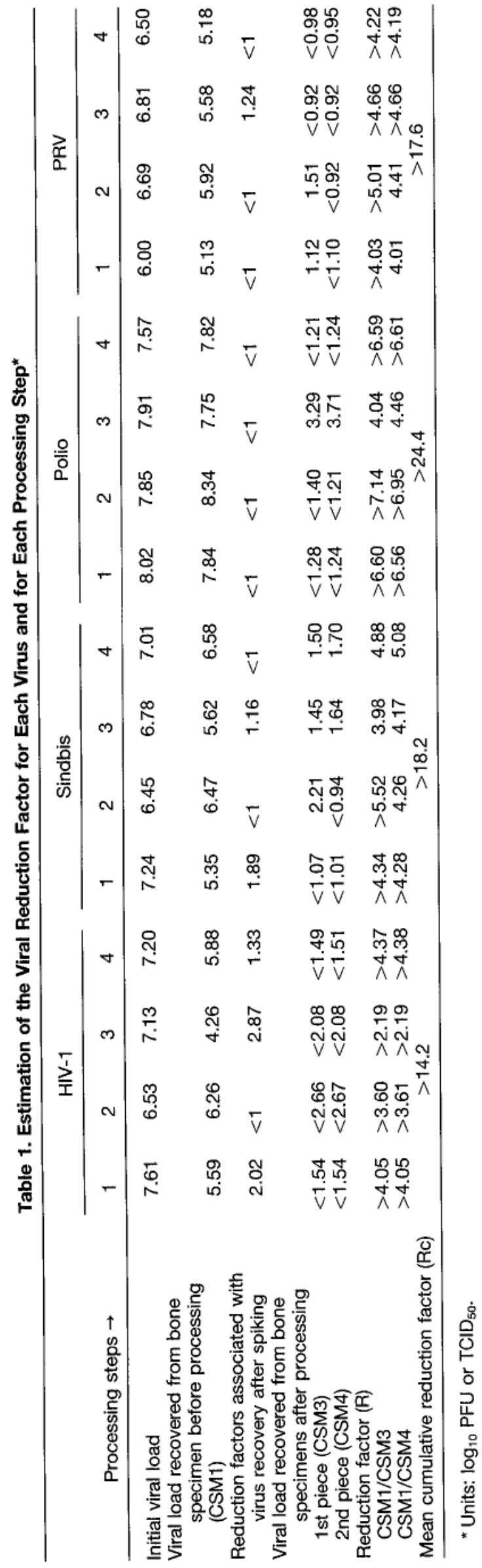

cessing treatments being more efficient in inactivating certain viruses.

\section{Discussion}

According to the EC guidelines, a treatment has a strong inactivating or eliminating effect on viruses when the associated reduction factor is higher than $\log _{10} 4$. In the current study, all four steps in the bone manufacturing process were found to be effective in eliminating or inactivating the tested viruses by generating reduction factors higher than $\log _{10} 4$ in all but two cases. These two exceptions involved the processing of HIV-1 at steps 2 and 3, when reduction factors of only $>3.61$ and $>2.19$ were obtained. However, these two low values were not process dependent, but were due to technical limitations of the viral inactivation assay.

The inclusion of the polio Sabin virus, which has no envelope and is therefore more resistant to physicochemical treatments, allowed us to use this study to distinguish between the relative efficiencies of the four processing steps. The results show that the sodium hydroxide step was the least effective in viral inactivation. It should be remembered that this step was introduced in the bone allograft process to prevent the risk of transmission of spongiform encephalopathies such as Creutzfeld-Jacob disease ${ }^{23}$; and it is noteworthy that the three other steps led to a total inactivation of the poliovirus, giving high mean reduction factors in the range of $\log _{10} 6$ to $\log _{10} 7$.

When a reduction in the level of viral activity is observed experimentally, it may be due to either an elimination or an inactivation of the viral load. When both phenomena occur simultaneously, it is not easy to distinguish between the contribution of each. For this study, a first approach is to consider that steps 2, 3, and 4 involve only an eliminating mechanism, whereas both elimination and inactivation could have been achieved during step 1 . This hypothesis seems reasonable because the first step is primarily aimed at removing fat tissue from bones, and the use of supercritical $\mathrm{CO}_{2}$ fluid extraction has already been described as effective in sterilizing against microorganisms. ${ }^{24}$ For safety reasons, the potentially contaminated lipidic material extracted was not available for viral titration. As a consequence, the individual contribution of inactivation and elimination to the level of viral reduction could not be assessed experimentally.

However, it is possible to hypothesize that artifactual viral elimination could have occurred during steps 2 and 4 because the most resistant virus to inactivation, the poliovirus, gave significantly higher reduction factors than those viruses with envelopes. This is the case if we compare poliovirus with Sindbis virus in steps 2 and 4 (>6.95 compared with 4.26 , and $>6.61$ compared with 5.08), respectively, and poliovirus with PRV in step 2 (>6.95 compared with 4.41).

When studying solid materials, the measurement and detection of viral activity must take into account the possible artifactual viral loss due to the experimental protocol. In this study, the viral load of each bone specimen was determined after pulverizing the bone, immersing it in cell culture medium, and virally titrating the supernatant. If the viral recovery protocol had been compromised because, for example, a virus-bone linkage, the actual viral load would have been underestimated, possibly leading to an overestimation of the corresponding reduction factor. Two possible phenomena might be involved 
in this situation. Either the virus could be strongly bound to the bone matrix, or the viral suspension could precipitate inside the bone fragments. In the current study, because the recovery rate of the poliovirus before and after processing at steps 2 and 4 was satisfactory (i.e., the loss was $<\log _{10} 1$ ), the first hypothesis, concerning the binding of the virus, can be excluded. However, the precipitation hypothesis may still apply.

Another hypothesis regarding factors that may have influenced these results lies in the fact that the bone matrix could have a protecting effect on viruses with envelopes. Although we are unable to comment further about this possibility, such considerations show the complexity of the various parameters that influence the measurement of viral inactivation and elimination, and clearly demonstrate the need for strict protocols that include a number of controls.

\section{Conclusions}

The process of supercritical $\mathrm{CO}_{2}$ fluid extraction has been demonstrated to be effective in eliminating or inactivating the viral activity of all four of the viruses tested in this study, generating reduction factors higher than four orders of magnitude. By combining the effect of four sequential processing steps, the amount of viral elimination or inactivation for the whole process generated cumulative reduction factors, $\mathrm{Rc}$, ranging from $>14.2$ to $>24.4$. This study clearly shows that the supercritical fluid extraction process is an advantageous technique for processing bone allografts for transplantation, either to replace or to augment current treatments. In addition to resolving the question of viral safety, another major advantage of this process lies in the fact that all medullary tissues, which can be responsible for an adverse immune response, are completely removed. It has previously been shown that their removal leads to a more open bone porosity and contributes to better osseointegration of the bone graft. ${ }^{25}$

\section{References}

1. Aro HT, Aho AJ: Clinical use of bone allografts. Ann Med 25: 403-412, 1993.

2. Friedlander GE: Bone allograft: the biological consequence of immunological events. J Bone Joint Surg Am 73: 1119-1122, 1991.

3. Enneking WF, Mindell ER: Observations on massive retrieved human allografts. J Bone Joint Surg Am 73: 1123-1142, 1991.

4. Horowitz MC, Friedlander GE: Immunologic aspects of bone transplantation: a rationale for future studies. Orthop Clin North Am 18: 227-233, 1987.

5. Aspenberg $\mathrm{P}$, Thoren $\mathrm{K}$ : Lipid extraction enhances bank bone incorporation: an experiment in rabbits. Acta Orthop Scand 61: $546-548,1990$.

6. Tomford WW: Transmission of disease through transplantation of musculoskeleton allografts. J Bone Joint Surg Am 77: 17421754,1995

7. Conrad EU, Gretch DR, Obermeyer KR, et al: Transmission of the hepatitis-C virus by tissue transplantation. J Bone Joint Surg Am 77: 214-224, 1995.

8. Salzman NP, Psallidopoulos $M$, Prewett AB, O'Leary R: Detection of HIV in bone allografts prepared from AIDS autopsy tissue. Clin Orthop 292: 384-390, 1993.

9. Tomford WW: Surgical bone banking, in Tomford WW (ed), Musculoskeletal Tissue Banking, New York, Raven Press, 1993, pp. 19-56.

10. Campbell DG, Peng Li, Stephenson AJ, Oakeshott RD: Sterilization of HIV by gamma irradiation: a bone allograft model. Int Orthop 18: 172-176, 1994.

11. Koehler P, Glas JE, Larsson SA, Kreicbergs A: Incorporation of nonviable bone grafts: autoclaved autogeneic and frozen allogeneic bone grafts compared in the rabbit. Acta Orthop Scand 58: 54-60, 1987.

12. Aspenberg P, Johnson E, Thorngren KG: Dose-dependent reduction of bone inductive properties by ethylene oxide. / Bone Joint Surg Br 72: 1036-1037, 1990.

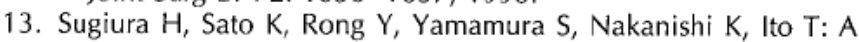
mechanical and biological study of surface demineralized and heat-treated cortical bone. European Journal of Experimental Musculoskeletal Research 3: 157-163, 1994.

14. Fages J, Marty A, Delga C, Condoret JS, Combes D, Frayssinet P: Use of supercritical $\mathrm{CO}_{2}$ for bone delipidation. Biomaterials 15: 650-656, 1994.

15. McHugh M, Krukonis VJ: Supercritical Fluid Extraction, 2nd ed, Boston, Butterworth Heinemann, 1994.

16. De Philippi RP: $\mathrm{CO}_{2}$ as a solvent: application to fats, oils and other materials. Chem Indust 19: 390-399, 1982.

17. Mellonig JT, Prewett AB, Moyer MP: HIV inactivation in a bone allograft. J Periodontol 63: 979-983, 1992.

18. Fages J, Frayssinet P, Asimus E, Mathon D, Autéfage A: Comportement in vivo d'un tissu oseux traité par fluide supercritique. Rev Med Vet 146: 655-662, 1995.

19. EC Regulatory Document: Note for guidance, IIt/8115/89-EN. Validation of virus removal and inactivation procedures. Biologicals 19: 247-251, 1991

20. Gregersen J, Wege H, Preiss L, Jentsch K: Detection of human immunodeficiency virus and other retroviruses in cell culture supernates by a reverse transcriptase microassay. I Virol Methods 19: $161-168,1988$.

21. Harada S, Koyanagi $Y$, Yamamoto N: Infection of HTLV-III/LAV in HTLV-I carrying cells MT-2 and MT-4 and application in a plaque assay. Science 229: 563-566, 1985.

22. Kaplan MM, Koprowski H (eds): Laboratory Techniques in Rabies, 3rd ed, Geneva, World Health Organization, 1973.

23. Kretzschmar HA: Human prion diseases (spongiform encephalopathies). Arch Virol 7: 261-293, 1993.

24. Ishikawa $H$, Shimoda $M$, Shiratsuchi $H$, Osajima $Y$ : Sterilization of microorganisms by the supercritical carbon dioxide microbubble method. Biosci Biotech Biochem 59: 1949-1950, 1995.

25. Thoren K, Aspenberg P, Thorngren KG: Lipid extracted bank bone. Clin Orthop 311: 232-246, 1995. 